Artigo

\title{
Escola Sem Partido e Ideologia de Gênero: \\ reflexões sobre a educação e a luta pela construção de uma sociedade justa
}

\begin{abstract}
School Without Party and Gender Ideology:
reflections on education and the struggle to build a just society
\end{abstract}

Escuela Sin Partido e Ideología de Género: reflexiones sobre la educación y la lucha por construir una sociedad justa

L'École Sans Parti et Sans Idéologie de Genre :

des réflexions sur l'éducation et la lutte pour la construction d'une société juste 
1 Graduada em Psicologia pela Universidade Estadual de Londrina, Londrina PR, Brasil; especialização em Gestão Pública pela Faculdade Estadual de Ciências Econômicas de Apucarana, Apucarana, PR, Brasil; mestre em Psicologia Social pela Pontifícia Universidade Católica de São Paulo, São Paulo, SP, Brasil, e doutoranda pelo Programa de Pós-Graduação em Psicologia Social da Universidade de São Paulo, São Paulo, SP, Brasil. Atua como Analista em Desenvolvimento Humano e Social da Empresa Brasileira de Pesquisa Agropecuária no Setor de Prospecção e Avaliação de Tecnologias que integra a Área de Transferência de Tecnologias, Salvador, Bahia, Brasil.

E-mail: neizabatista78@gmail.com

2 Graduada em Psicologia e mestre em Psicologia Clínica pela Pontifícia Universidade Católica de São Paulo, São Paulo, SP, Brasil; especialista em Psicopatologia do Bebê pela Universidade Paris Nord 13 - Paris, França; doutoranda pelo Programa de Pós-Graduação em Saúde Pública e pesquisadora do Laboratório de Saúde Mental Coletiva da Universidade de São Paulo, São Paulo, SP, Brasil.

E-mail: loumuniz@gmail.com

3 Graduado em Terapia Ocupacional e mestrando pelo Programa Humanidades, Direitos e Outras Legitimidades da Universidade de São Paulo, São Paulo, SP, Brasil.

E-mail: fegemelgo@gmail.com

${ }^{4}$ Graduada em Psicologia e mestra em Saúde Pública e doutoranda pelo Programa de Pós-Graduação em Psicologia Social da Universidade de São Paulo, São Paulo, SP, Brasil; especialização em Psicologia da Saúde pela Universidade Federal de São Paulo, São Paulo, SP, Brasil.

E-mail: lucilajmg@gmail.com

5 Graduada em Ciências Sociais pela Universidade Estadual Paulista, Araraquara, SP, Brasil, e em Psicologia pela Universidade Federal de São Carlos, São Carlos, Brasil; mestranda pelo Programa de Pós-Graduação em Psicologia Clínica e do Laboratório de Psicanálise e Sociedade da Universidade de São Paulo, São Paulo, SP, Brasil.

E-mail: lirufine@gmail.com

${ }^{6}$ Médico Veterinário graduado pela Universidade Federal Rural do Semi-Árido, Mossoró, RN, Brasil; mestre pelo programa de Pós-Graduação em Medicina Veterinária pela Universidade Federal de Campina Grande, Campina Grande, PB, Brasil;. doutorando no Programa de Pós-graduação em Clínica Cirúrgica Veterinária da Universidade de São Paulo., São Paulo, SP, Brasil.

E-mail: renatootaviano18@gmail.com

Batista, Neiza., Atem, Lou., Gemelgo, Felipe., Gonçalves, Lucila., Nolasco, Ligia., \& Rego, Renato. RG\&PP, 9(1): 
Resumo

Abstract
Este artigo é resultado do esforço coletivo para a conclusão de uma disciplina de Preparação Pedagógica para o Ensino Superior, cuja sugestão foi um debate focado no eixo Educação e Gênero. A partir desta proposta, pretendemos problematizar o discurso da Escola sem Partido, projeto de lei que se diz politicamente neutro, mas se mostra, pelo contrário, aderido ao combate da chamada ideologia de gênero, carregando valores de moral e religião bem específicos, característicos de uma visão conservadora e de perpetuação das desigualdades de gênero. Para a discussão, retomamos principalmente a concepção da educação enquanto prática emancipadora, tal qual abordada por Adorno e Paulo Freire, pois ambos supõem sujeitos ativos e questionadores, potencialmente transformadores da sociedade e, portanto, com potencial para a superação do sexismo e machismo. Como conclusão, reafirmamos a educação como lócus privilegiado e fundamental para que possamos avançar em tantas questões relativas à violência e discriminações estruturais entre homens e mulheres.

Palavras-Chave: Educação; Gênero; Desigualdade; Sociedade; Política.

This article results from a collective effort to complete a Pedagogical Preparation course for Higher Education and its suggestion of a debate focused on Education and Gender issues. From this proposal, we choose to problematize the discourse of the "School without Party" law project, that despite claims to be politically neutral, seems to be an opposition to the so-called gender ideology, carrying very specific values of morality and religion, characteristic of a conservative view and which mainten gender inequalities. Regarding to support our discussion, we mainly used the conception of 
education as an emancipatory practice, as discussed by Adorno and Paulo Freire, since both assume active and questioning individuals, with potential to social transformation and so on to the overcoming of sexism. In conclusion, we reaffirm education as a privileged and fundamental locus for advancing in so many issues relating to violence and structural discrimination between men and women.

Keywords: Education; Gender; Inequality; Society; Politics.

\section{Resumen}

Este artículo es resultado del esfuerzo colectivo para la conclusión de una asignatura de Preparación Pedagógica para la Enseñanza Superior, cuya sugerencia fue un debate concentrado en Educación y Género. Siguiendo esta propuesta, vamos a problematizar el discurso de la Escuela sin Partido, proyecto de ley que se dice políticamente neutro, pero al revés, se muestra adherido al combate de la llamada ideología de género y cargado de valores morales y religiosos muy específicos, característicos de una visión conservadora y perdurable de las desigualdades entre hombres y mujeres. Para la discusión, retomamos sobre todo el concepto de educación como práctica emancipadora planteada por Adorno y Paulo Freire, pues ambos suponen sujetos activos, cuestionadores y potencialmente transformadores de la sociedad y, por lo tanto, con capacidad para la superación del sexismo y el machismo. Al final, reafirmamos la educación como lugar privilegiado y fundamental para los avances de muchos temas relativos a la violencia y discriminaciones estructurales de género.

Palabras Clave: Educación; Género; Desigualdad; Sociedad; Política. 
Resumé

Cet article provient de l'effort collectif pour compléter un cours de préparation pédagogique pour l'enseignement supérieur, avec la suggestion d'un débat sur l'éducation et le genre. Sur la base de cette proposition, nous avons l'intention de discuter la parole de I "École sans Parti", le projet de loi qui est proclamé politiquement neutre, mais il se trouve, cependant, a rejoint l'appel du combat "l'idéologie du genre ", portant des valeurs morales et religieuses très spécifiques, caractéristique d'une vision conservatrice et de la perpétuation des inégalités de genre. Pour la discussion, on a pris la conception de l'éducation comme pratique d'emancipation, comme est adressé par Adorno et Paulo Freire, puisque les deux supposent des sujets actifs et interrogateurs, transformant potentiellement notre société et donc l'engagement de soutenir le changement social, y compris le dépassement du sexisme et du machisme. En conclusion, nous réitérons l'éducation en tant que lieu privilégié et fondamental afin que nous puissions passer tant de questions ayant trait à la violence et à la discrimination structurelle entre les hommes et les femmes.

Mots-Clés: Education; Genre; Inégalité; Société; Politique. 


\section{Introdução: desigualdade de gênero e a proposta de lei}

No ano de 2018, por ocasião do Dia da Mulher, o IBGE divulgou o boletim "Estatísticas de Gênero: indicadores sociais das mulheres no Brasil", no qual apresenta dados acerca da desigualdade de gênero no Brasil, revelando discrepâncias entre homens e mulheres em diversos aspectos da vida cotidiana. Os dados revelam que as mulheres têm maior dedicação aos afazeres domésticos, e que apesar de terem um percentual de escolaridade superior maior que o dos homens (com maior concentração em profissões assistenciais, pois são vistas como naturalmente "maternais"), continuam a ter média salarial inferior e menos frequência em cargos gerenciais ${ }^{1}$. No campo político, têm representação ínfima, com apenas 10,5 \% de deputadas na câmara, por exemplo.

Tais diferenças também estão refletidas em dados sobre outras violências e divisões. De acordo com o Fórum Brasileiro de Segurança Pública - FSBP (2018), no Brasil uma mulher é assassinada a cada duas horas. e nosso país ocupa a 7a posição entre as nações mais violentas para o gênero feminino, de um total de 83 nações, segundo relatório da Organização Mundial da Saúde (OMS). O Conselho Nacional de Justiça - CNJ (2017) divulgou também, em 2017, o registro de 290.423 inquéritos policiais novos sobre violência doméstica e familiar contra a mulher na Justiça Estadual do país. Trata-se, para usar um termo de Adorno (1995), de uma situação de completa barbárie.

Se por um lado observamos mudanças importantes, como o aumento do nível de escolaridade das mulheres, as demais estatísticas mostram que as diferenças entre homens e mulheres permanecem, no que se refere, especialmente, à possibilidade de tempo livre, às relações no mundo do trabalho, à representatividade política e segurança pública. Os espaços públicos e políticos (de poder) são centrados no universo masculino, e os espaços privados (lares) ou profissões de cuidado são "ditas" femininas. Pautadas pelo sexo, tais relações determinam à mulher diversos limites quanto às suas decisões, espaços de atuação, natureza das atividades exercidas, valorização de si, dignidade, entre outros aspectos.

10 tempo dedicado a afazeres domésticos é 18,1 horas semanais para as mulheres, enquanto os homens gastam 10,5 horas. Entre a população branca, 23,5 \% das mulheres e 20,7\% dos homens têm ensino superior e entre a população preta ou parda, os dados são de 10,4\% das mulheres e 7\% dos homens. A média salarial dos homens é de $\mathrm{R} \$ 2.306,00$ e das mulheres, $\mathrm{R} \$ 1.764,00$. Nas empresas, $62,2 \%$ dos cargos gerenciais são ocupados por homens. 
Com esta organização da vida social fundada no modelo patriarcal, mantemos a violência e diferença em suas formas, desde o uso da linguagem até a manifestação da força física, com as coerções: emocional, moral, física, sexual e laboral às mulheres. Esta realidade, produtora e reprodutora de sofrimento em grande dimensão, é muitas vezes naturalizada e nem sempre reconhecida como algo que foi absolutamente construído ao longo da história social. Marcadas por redes de poder “... que influenciam o modo de viver do ser humano, na condição de um ser atuante, onde a sexualidade exerce um papel essencial tanto no particular como no geral" (Leão et. al, 2007:77), ainda que representem uma maioria numérica $(51,03 \%)^{2}$, as mulheres continuam existindo como minoria política e cultural, ou como um "pequeno número", segundo a nomeação apresentada por Appadurai (2009) para abordar violências em larga escala.

Neste cenário, onde já parecia urgente o reconhecimento da hierarquia imposta secularmente, surge em 2004, no Brasil, o Movimento Escola Sem Partido (MESP), que traz como pauta uma "reação às práticas educacionais que seus defensores definem como 'doutrinação política e ideológica na sala de aula' e 'usurpação do direito dos pais sobre a educação moral e religiosa de seus filhos', alinhado aos embates em torno da chamada 'ideologia de gênero."' (Miskolci \& Campana, 2017:729) Nossa proposta é pensarmos alguns conteúdos do Projeto de Lei Escola sem Partido a partir de uma perspectiva de educação enquanto prática emancipadora, evidenciando contradições do projeto de lei em relação à uma educação que busca a liberdade e o progresso social, com a diminuição das desigualdades.

\section{Contextualizando o Projeto de Lei Escola Sem Partido}

O MESP surgiu em 2003 a partir de uma iniciativa particular de seu fundador, Miguel Nagib, procurador do Estado de São Paulo, e foi oficializado em 2004, concomitante com a posse do presidente Luiz Inácio Lula da Silva, cuja pauta priorizava um plano de governo comprometido com a justiça social. Este movimento veio à tona novamente, com maior força, justo no período do golpe que impediu a presidenta Dilma Rousseff a continuar seu mandato. No atual cenário de disputas políticas, há um evidente acirramento das tensões entre proposições mais progressistas (aliadas inclusive a agendas internacionais) e aquelas mais conservadoras, ligadas à burguesia e às bancadas religiosas como a Frente Parlamentar Mista Católica Apostólica Romana e a Frente Parlamentar Evangélica.

De acordo com o blog do MESP, o projeto de lei foi uma iniciativa conjunta de estudantes e pais preocupados com a "contaminação" ideológica e política das escolas brasileiras, sendo criado para "dar visibilidade a um problema gravíssimo que atinge a imensa maioria das escolas e universidades brasileiras: a instrumentalização do ensino para fins políticos, ideológicos e

\footnotetext{
${ }^{2}$ Segundo o último censo realizado no Brasil, em 2010.
} 
partidários". O MESP se declara contra o modelo de educação proposto por Paulo Freire, denominado por eles de doutrinação. Um aspecto interessante, é que:

Apesar do discurso do movimento tentar criar para si uma imagem de defensor da escola contra o que chama de "contaminação político-ideológica", o criador do movimento, Miguel Nagib, tem profundos vínculos com o think-tank ${ }^{3}$ liberal Instituto Millenium, tendo sido por muito tempo articulista e depois um dos mantenedores do instituto. 0 Instituto Milenium é "o principal think-tank da direita brasileira, criado em 2006 e financiado por empresas nacionais e transnacionais, com eco na linha editorial de parte da grande imprensa e popularizada por jornalistas como Rodrigo Constantino." (Miguel, 2016, citado por Moura, 2016:23-24).

Ao historicizar o movimento, esta mesma autora menciona que este se manteve muito tempo sem grande expressividade, encontrando eco na sociedade em alguns momentos específicos: em 2007, por ocasião de uma polêmica gerada por críticas à coleção de livros didáticos Nova História Crítica, de Mario Schmidt. Posteriormente, em 2011, por conta das objeções em torno do material de "Combate à Homofobia" produzido pelo Ministério da Educação e chamado pela mídia de "Kit Gay" - nesse momento, os combatedores da "ideologia de gênero" passaram a nomear tais ações como "doutrinação marxista", trazendo a "moralidade" para a "política" e a disputa entre a escolarização e a autoridade da "família". E em 2014, quando sua expansão se situa na crise de polarização da sociedade em torno das campanhas presidenciais da então presidenta Dilma Rousseff e do senador Aécio Neves.

Com o fortalecimento das demandas de um pequeno número, no caso as mulheres, instala-se na sociedade um profundo sentimento de incerteza sobre o futuro, no que tange às identidades dominantes e seu relacionamento com o Estado, do qual a escola faz parte. Um mecanismo comum de reação grupal a esta incerteza, é a (re) afirmação de diversas outras certezas, doutrinárias, que inflexibilizam o debate e se fortalecem, muitas vezes, no argumento de uma distorcida democracia: há o encorajamento da legitimação política vigente (dos grandes números), em um processo simultâneo de exclusão das necessidades e interesses de grupos considerados menores, sendo manipuladas fantasias sobre "riscos aos interesses gerais" que estes grupos supostamente oferecem (Appadurai, 2009:52-53) - como no caso do projeto de lei em questão, riscos abstratos à família e à liberdade. Estas reações estão baseadas em uma compreensão superficial e limitada de coletividade, de cidadania, de comunidade, ou como apresentou Appadurai (2009:65-66) seguindo a tradição Freudiana, de um "narcisismo das pequenas diferenças".

Segundo o autor, podemos compreender estes processos de resistência contra a pauta de uma minoria política como um "medo aos pequenos números". Este medo surge justamente em momentos em que o status quo em uma sociedade, ou o privilégio de uma maioria, passa a ser questionado. Isso porque quando as minorias reivindicam direitos, como a luta por igualdade

3 Um Think-Tank é em geral um grupo de interesse ou uma instituição que investe em divulgação e propagação de conhecimento com viés político-ideológico definido e ligado a interesses particulares deste grupo, visando transformações na sociedade. 
entre os gêneros, colocam em xeque as idealizações de uma nação supostamente completa, uniformizada, ou seja, de um "projeto nacional" sacralizado - segundo é claro, a perspectiva dos grupos dominantes, as "maiorias". Estas dinâmicas de oposição e conflito fazem surgir o que o autor chama identidades predatórias, que mobilizam um entendimento sobre si como uma maioria ameaçada e que reivindicam, então, a extinção das coletividades "menores" ou de suas exigências (Appadurai, 2009:45-46). O autor menciona que a uniformização educacional é uma das estratégias utilizadas pelas identidades predatórias para o controle social (Appadurai, 2009:14).

É importante relembrar que as mulheres são uma maioria numérica e que reivindicam questões relacionadas à sua existência e dignidade. Neste sentido, a educação deve se posicionar a favor do processo emancipatório. 0 que se percebe, porém, são ataques frequentes às discussões relativas a gênero, classes sociais, política, que passam inclusive a ser criminalizadas (para que sejam silenciadas). Diante disto, nos indagamos sobre as possibilidades de transformação social. Ora, que futuro desejamos para uma sociedade já tão marcada pelas violências que caracterizam nossa herança patriarcal, se não pudermos nos questionar acerca dela? Que caminhos nos levarão a uma sociedade diferente desta se os dados apresentados por instituições reconhecidamente atuantes em prol da construção da cidadania brasileira, nos fazem reconhecer uma realidade cruel e excludente?

\section{Sobre a Educação e a Gênero pela Construção de uma}

\section{Sociedade Justa}

Para iniciar um diálogo sobre educação, se faz necessário definir qual o modelo de sociedade queremos e, a partir disto, o que entendemos como educação. Tendo em vista a discussão realizada na Introdução e Contextualização deste artigo, tomamos como modelo de sociedade aquela que traz uma organização embasada em princípios de equidade e justiça, que se contrapõem ao status quo hoje vivido a partir de hierarquizações das relações de gênero (Silva, 2007; Tonet, 2012). Nesta perspectiva, propomos pensar a educação como uma possibilidade de emancipação humana, apesar da contradição já implícita, uma vez que esta é vivenciada dentro de um sistema estruturalmente excludente e discriminatório.

Ivo Tonet (2012) em "A Educação contra o Capital", trata o conceito de trabalho como uma atividade social de transformação da natureza, que traz sentidos e significados ao ser humano, afirmando que a educação não pode separar-se desta categoria pois supõe a mesma raiz ontológica do ser social. Nesta perspectiva: 
a natureza essencial da atividade educativa consiste em propiciar ao indivíduo a apropriação de conhecimentos, habilidades, valores, comportamentos, etc. que se constituem em patrimônio acumulado e decantado ao longo da história da humanidade" (p. 69).

Este pensamento também é discutido em Freire (1979), que apresenta a educação justamente como um espaço formador, onde ocorreria a percepção da sociedade como um todo, suas faltas e problemas, proporcionando o esforço coletivo de reflexão crítica, que permitiria o exercício da cidadania e co-criação de novas formas de estar no mundo. Para Adorno (1995) este espaço é necessário pois deve abordar a elaboração do passado, a partir de uma educação esclarecedora, como uma das armas mais potentes para evitar a repetição de barbáries já cometidas e daquelas que permanecem latentes.

Tendo estas questões destacadas, e sabendo que o espaço escolar está apropriado por representantes de muitas formas de diversidade, cabe-nos aqui o seguinte questionamento: como atuar a partir do pluralismo de ideias no ambiente acadêmico e da liberdade de aprender e de ensinar e, ao mesmo tempo, respeitar "o direito dos pais dos alunos a que seus filhos recebam a educação religiosa e moral que esteja de acordo com as suas próprias convicções"? (ESP, 2016, Artigo 5º Inciso V). Partindo desta indagação, acreditamos que é possível trabalhar os conteúdos pedagógicos em sala de aula com uma abordagem transversal que ultrapassa as crenças individualizadas de cada família e que, ao mesmo tempo, não exclui cada uma das famílias presentes em sala de aula, já que a realidade social do país afeta o cotidiano de todas. Assim, temas como: "violência doméstica, sexualidade, família, reprodução, atuação profissional, democracia, ética, direitos, cidadania são temas que batem à porta das escolas e adentram as salas de aula junto com alunos(as) e professores(as), pois fazem parte de seu quotidiano social." (Silva, 2011: 132).

Neste sentido, cabe-nos mais uma vez refletirmos a que ou a quem uma "neutralidade política e ideológica" serve quando a definimos como um princípio a ser seguido entre as diretrizes educacionais de uma sociedade perpassada por tantas desigualdades. É incoerente traçar uma estratégia pedagógica de pensamento único e ignorar que:

a mulher vítima de violência não estivesse na sala de aula, quer como professora, quer como aluna; como se o agressor não pudesse ser o professor ou o aluno ou seus pais, irmãos etc.; como se não houvesse homossexual em sala, nem lésbica, nem mãe solteira, nem grávida... Há, na verdade, um paradoxo comportamental em face dessas temáticas que, quando não são silenciadas, são tratadas com um viés preconceituoso ou dicotômico, gerando mais e mais preconceito e reforçando a segregação de seres historicamente excluídos do exercício da cidadania, como as mulheres, homossexuais, negros, entre outros. (Silva, 2011:132 -133).

A compreensão de que as relações desiguais de poder se baseiam em práticas normativas difundidas na cultura e reforçadas nas instituições sociais, dentre estas, a escola, é fundamental. Por esta razão, a escola assume um papel muito importante tanto na construção como na manutenção ou transformação das relações sociais das quais toda sua comunidade participa. Sob a perspectiva de educação emancipadora, este espaço tem o dever ético de se opor ao funcionamento discriminatório, como forma de oposição também à barbárie. Deve, então, fomentar o debate, a reflexão e novos comportamentos que busquem a superação das tradições 
violentas, entre as quais, estão as relações desiguais entre os gêneros. Para Adorno (1995), tratase de um compromisso no qual:

É preciso reconhecer os mecanismos que tornam as pessoas capazes de cometer tais atos, é preciso revelar tais mecanismos a eles próprios, procurando impedir que se tornem novamente capazes de tais atos, na medida em que se desperta uma consciência geral acerca desses mecanismos (....) É necessário contrapor-se a uma tal ausência de consciência, é preciso evitar que as pessoas golpeiem para os lados sem refletir a respeito de si próprias. A educação tem sentido unicamente como educação dirigida a uma auto-reflexão crítica (p. 121).

De modo complementar, Silva (2011) assinala que a revisão de currículos, de materiais e estratégias didáticas, de teorias, de normas e da própria linguagem na escola, tem papel imprescindível para que esta possa se tornar um ambiente acolhedor e efetivo ao debate sobre "gênero e cidadania" nos processos de aprendizagem. Reforça, então, que a instituição não deve se restringir à reprodução de conteúdos exigidos em vestibulares ou pelo mercado de trabalho aquilo que Paulo Freire conceitua como educação bancária -, mas também, participar da intervenção social.

Tonet (2012) afirma ser vivenciada na escola, via políticas educacionais, a expressão de diversas questões político-ideológicas, onde ocorrem, muitas vezes, a reprodução de preconceitos e estereótipos, ao invés do exercício de transformação das diferenças em pluralidade. Um bom exemplo disso é a atribuição às meninas do papel da disciplina, limpeza e organização no ambiente escolar, exigindo delas comportamentos construídos socialmente e que não necessariamente correspondem às suas escolhas. Neste sistema, há desdobramentos que continuam no ambiente futuro de trabalho, como explica Bruschini (1989):

Da mesma forma que o mercado de trabalho, o ensino formal, em seus diversos níveis, apesar da igualdade constitucional de oportunidades educacionais entre homens e mulheres, e da miscigenação sexual teórica e legal das escolas, vem atuando no sentido de segregar os sexos por ramos e áreas de conhecimento. A consequência direta em termos de trabalho profissional é que este sistema vem fornecendo (pelo menos) argumentos para a segregação ocupacional, que constitui um fator limitador da participação da mulher na força de trabalho. Isto, por sua vez, acarreta diferença de salários e de "status" entre os trabalhadores masculinos e femininos (citado por Rosemberg, 1994:10).

Assim, diferente do que pontua o MESP, a argumentação de Paulo Freire não pretende doutrinação, mas situa a educação em um contexto de opressão. Este princípio, ao contrário de ser "metafísico e vago", faz sentido na atual realidade em que a estruturação pautada em hierarquias (de gênero, raça e idade, por exemplo), traz desigualdades quanto ao acesso de direitos e nas relações interpessoais, que são cotidianamente experenciados/as nos espaços educativos.

Sob a perspectiva de uma educação que se propõe a trazer mudanças ao status quo presente, não cabe pensar o professor como ser superior que ensina ignorantes, ao contrário disto, educador e educando se encontram em uma tarefa na qual ambos são sujeitos no ato que inclui o recriar do conhecimento. Sendo assim, o posicionamento de audiência cativa, que estabelece a vulnerabilidade do educando como a parte "passiva" da relação, proposto pelo 
MESP, retira a capacidade criativa da educação, colocando-a em um processo adaptativo sem sujeito, tornando a relação aluno-professor objetificante e estritamente hierarquizada.

A sociedade que queremos construir, mais justa, dependerá também da construção de novas formas de educar. Afinal, qual a possibilidade de mudança em uma sociedade que busca a repetição de si própria e de seus valores culturais e não fomenta a possibilidade criativa? E, por que imbuir às organizações de respaldo à educação um papel policialesco, se somos todos sujeitos do processo educativo?

Como é apresentada por Paulo Freire:

A realidade social, objetiva, que não existe por acaso, mas como produto da ação dos homens, também não se transforma por acaso. Se os homens são os produtores desta realidade e se esta "na invasão da práxis, se volta sobre eles e os condiciona, transformar a realidade opressora é tarefa histórica, é tarefa dos homens. (1970:20).

Neste sentido, não é possível imaginar "os limites éticos e jurídicos da atividade docente", tão defendidos pelo Movimento Escola sem Partido, sem necessariamente prever a liberdade de aprender e de ensinar e a liberdade de consciência e de crença dentro de uma lógica dialética, a partir da qual professores e alunos passam a refletir sobre conteúdos e processos educacionais, entendendo que a dimensão educativa não pode ser vista de modo isolado, mas compondo uma totalidade atravessada pela diversidade: de modelos de família, de interesses e necessidades, de crenças e valores.

\section{Ideologia de Gênero e a Manutenção de uma Sociedade}

\section{Conservadora e Excludente}

O termo "ideologia de gênero" foi disseminado em nossa sociedade especialmente pela bancada conservadora do Congresso Nacional, sem quaisquer fundamentações conceituais. No entanto, buscando entender a respeito, encontramos a existência de um movimento mundial em torno desta concepção que a discute sob referências ditas "científicas", pautadas por um pensamento biológico de diferenças entre os sexos, e que orienta várias ações estratégicas, principalmente no sistema educacional. Desta maneira, não podemos restringir o combate à chamada ideologia de gênero a interesses exclusivamente religiosos ou de dimensão políticopartidária. É importante entrelaçar a leitura sobre o modelo de família patriarcal, o que amplia e reforça a importância da discussão proposta por este artigo.

De acordo com Jorge Scala, autor de La ideologia del género "a 'ideologia de gênero é um instrumento político-discursivo de alienação com dimensões globais que busca estabelecer um modelo totalitário com a finalidade de 'impor uma nova antropologia', a provocar a alteração das pautas morais e desembocar na destruição da sociedade" (citado por Miskolci \& Campana, 
2017:725). Partindo do fundamento moral, de vieses religioso e familiar, que questiona a "liberação do ser humano de sua biologia", o combate à chamada ideologia de gênero "... associase a diversas discussões que giram em torno da saúde reprodutiva das mulheres, da educação sexual ou do reconhecimento de identidades não heterossexuais, entre outras questões." (Miskolci \& Campana, 2017:725-726).

Tendo suas origens no seio da Igreja Católica, o combate à ideologia de gênero amplia-se na Europa e na América Latina, agregando grupos de outras religiões, sobretudo evangélicos neopentecostais, e também grupos desvinculados de tendências religiosas, mas aliados a uma moral conservadora que traz como princípio a noção de família tradicional burguesa, patriarcal e heterossexual.

Na Conferência Mundial de Beijing sobre a Mulher, organizada pelas Nações Unidas em 1995, houve a proposta de "substituir o termo 'mulher' (que havia sido o principal sujeito nas primeiras três conferências) pelo conceito gênero" (Miskolci \& Campana, 2017:727), estabelecendo esta categoria como parâmetro para as políticas da comunidade internacional. Essa deliberação veio no sentido de afirmar que o gênero é uma construção social e independe da condição biológica, o sexo. Como reação conservadora, a ideologia de gênero surge como crítica e tentativa de deslegitimar o que significou a conquista do termo "gênero" para a sociedade: combate à desigualdade e inferioridade explícita pela dominação pelo patriarcado. As raízes desta reação se fortaleceram dentro da Igreja Católica, que defende uma perspectiva essencialista à identidade feminina, sendo o matrimônio, a reprodução e maternidade elementos-chave. Trata-se de uma compreensão de que deslocar o papel da mulher na sociedade significaria o enfraquecimento da vida familiar e de tradições construídas.

Partindo de uma moral que atrela o respeito à vida ao conceito de família tradicional, diminuindo o respeito à autonomia da mulher enquanto sujeito, o combate à ideologia de gênero representa uma resistência aos avanços dos direitos das mulheres sobre seus próprios corpos e relações, assim como aos direitos referentes às identidades não normativas no tangente às sexualidades. Nesta perspectiva, esta pauta passou a interessar também às organizações próvida, às organizações evangélicas e outras supostamente não religiosas, como o MESP. Embora partindo de diagnósticos diferentes, tais grupos assumem o papel de empreendedores morais, tornando a luta contra a ideologia de gênero um eixo prioritário de ação política-discursiva.

Luna (2017) assinala justamente que:

Embora se reconheça o papel da Igreja no enfrentamento da ditadura militar no Brasil, na constituição de uma cultura de direitos estimulada pela Teologia da Libertação e no movimento das Comunidades Eclesiais de Base, participando de diversas causas relacionadas à justiça social, como reforma agrária, defesa dos povos indígenas e direitos dos trabalhadores, em que estaria alinhada à esquerda, no tocante aos direitos sexuais e reprodutivos, sua atuação tem sido marcante em outra direção (....) Quando se analisa a posição da Igreja Católica com respeito a demandas relacionadas com as liberdades individuais e o debate sobre direitos humanos salienta-se a importância do debate sobre o aborto e outros temas relacionados à dita "defesa da vida" como a eutanásia. 0 conflito entre a instituição religiosa de orientação conservadora e grupos em defesa de direitos humanos se explicita em diversas disputas no espaço público acerca de questões voltadas para a reprodução e sexualidade, caso do aborto, da contracepção e da diversidade sexual. (2017, s.p). 
Nesta realidade, os movimentos feministas e LGBT ganharam mais força e visibilidade somente na virada do milênio, ainda que sofrendo sob as forças repressoras. Não por acaso, estes embates emergiram sobremaneira em países que passaram a ter governos de esquerda, como foi no Brasil durante o governo Lula, por exemplo quando lançaram o programa "Brasil sem Homofobia". Segundo Miskolci \& Campana (2017:738), em 2011, com o reconhecimento da união homoafetiva pelo Supremo Tribunal Federal (STF), as oposições contra a chamada ideologia de gênero se inflamaram novamente e a polêmica gerou notoriedade nacional ao tema.

Ao analisar o processo de construção da Base Nacional Curricular Comum (BNCC), Elizabeth Macedo (2017) constata

que a entrada em cena das demandas conservadoras do ESP desloca ainda mais o jogo político no sentido do controle que exclui a diferença, ao mesmo tempo em que torna explícita essa exclusão". Na segunda versão da BNCC se materializou o fortalecimento de demandas conservadoras, que ganharam .... proeminência após o impeachment de Dilma Rousseff quando o ESP passou a ser um dos interlocutores do MEC (p. 509),

colocando em xeque a competência do Conselho Nacional de Educação (CNE) e do MEC para a definição da BNCC sob o argumento de que esta última deve tratar de currículo e não de direitos, o que caberia à Constituição, como se estas instâncias fossem indissociáveis.

De acordo com a divisão dos espaços público e privado e sua relação com os gêneros, apresentada na introdução deste artigo, percebe-se que os defensores do combate à ideologia de gênero ratificam a polarização entre professores e pais, reivindicando uma separação artificial entre os papéis destes na formação moral e ética durante o processo educacional. Esta suposição destitui o espaço da escola como espaço de diversidade, local de reflexão e formação crítica. Nas palavras de Macedo "Minha questão é o quanto o ESP ajuda a reviver, em nossa história, traumas de uma nação assentada no mito da inclusividade total erigido sobre a exclusão silenciosa do outro." (2017:518).

É este modelo de sociedade que desejamos?

\section{Considerações Finais}

No campo político, além de diferentes interesses, estão em disputa os afetos humanos. Esta variável, muitas vezes considerada menor, determina muitos aspectos "legais" da vida em sociedade. Isto porque a política é constituída por pessoas, e pessoas são constituídas por afetos, que não se relacionam de maneira objetiva/direta com a argumentação coerente ou com os compromissos ético-coletivos. A partir desta compreensão, daquilo que Safatle (2016) nomeou "circuito dos afetos", é possível esclarecermos porquê um projeto de lei como o da Escola sem Partido ganha amplo apoio social, apesar de seus aspectos problemáticos. 
Conforme apresentado ao longo deste trabalho, a história social e estatísticas atuais não deixam dúvidas sobre a desigualdade de gênero em nosso país. Da mesma maneira, está evidente que o projeto de lei Escola sem Partido carrega consigo valores específicos, que recuam no enfrentamento desta desigualdade, apesar de discursar sobre "proteção a direitos". Esta contradição, que poderia ser logicamente identificada, fica ofuscada por afetos que são mobilizados pelo Estado ao propor tal debate.

Para que uma lei, alinhada à manutenção da barbárie, consiga se impor e gerar convencimento sobre sua legitimidade em busca do "bem estar social" (princípio que supostamente direcionaria a criação de novas leis), ela precisa fazer circular os afetos "medo" e "esperança" no meio social. 0 medo se refere à ameaça contra as características (ou privilégios) individuais, contra aquilo pelo qual as pessoas se definem e se identificam. Cria-se, então, um medo paranoico ligado a uma possível guerra - discussão complementar à identificação cega com o coletivo descrita por Adorno (1995) e à formação de identidades predatórias apresentada por Appadurai (2009). Nestes cenários, o Estado se coloca como a instituição capaz de evitar esta guerra, de controlar o conflito. Em outras palavras, mobiliza a "esperança" de que, com a sua mediação (controle) a guerra não se realize.

A questão central é o que o conflito existe, e que a "guerra" se realiza cotidianamente em forma de violências de gênero. Há questões que não podem mais ser silenciadas, e o desconforto é previsto quando se pretende deslocar conceitos e práticas e desconstruir uma história de opressão. Neste cenário, em que os fazeres políticos são constantes e nunca neutros, onde as leis operam de maneira arbitrária para a manutenção do status quo, sem que precisem estar, necessariamente, fundadas em argumentos coerentes, pois desde que estejam alinhadas aos interesses dominantes e consigam afetar (no sentido do convencimento) a maioria numérica, passam a ser propagadas, afirmamos a urgente necessidade de debates profundos e críticos das propostas de legislação sobre nossas vidas. Ademais, entendendo a educação como um espaço de grande importância no caráter formador e transformador de nossa sociedade, na medida em que pode ser tomada a partir de uma prática emancipatória, em que o aluno constrói seu aparato social e simbólico, de forma ativa, reafirmamos sua função para que as mudanças essenciais em nossa sociedade possam ser garantidas e para que os cenários de barbárie, conforme afirma Adorno (1995) não se repitam.

Dessa forma, tomando as relações de desigualdade de gênero como algo intrinsecamente ligado a disputas de poder, devemos lutar pelas superações possíveis das faltas humanas, ao invés de concedermos submissão aos interesses de quem toma a educação para interesses próprios. 


\section{Referências Bibliográficas}

Adorno, Theodor W. (1995). Educação após Auschwitz. Em: Educação e Emancipação. 3a Ed. São Paulo: Paz e Terra. Tradução de Wolfgang Leo Maar. p. 119-154.

Appadurai, Arjun. (2009). O medo ao pequeno número: ensaio sobre a geografia da raiva. São Paulo: Iluminuras.

Conselho Nacional de Combate à Discriminação. (2004). Brasil Sem Homofobia: programa de combate à violência e à discriminação contra GLBT e promoção da cidadania homossexual. Brasília: Ministério da Saúde. Acesso em 13 de maio de 2018 de: http://bvsms.saude.gov.br/bvs/publicacoes/brasil sem homofobia.pdf

FBSP - Fórum Brasileiro de Segurança Pública. (2018). Atlas da Violência 2018. Rio de Janeiro, RJ: IPEA e FBSP. Acessado em 30 de abril de 2018, de http://www.forumseguranca.org.br/wpcontent/uploads/2018/06/FBSP Atlas da Violencia 2018 Relatorio.pdf

Projeto de lei do senado № 193, de 2016. Inclui entre as diretrizes e bases da educação nacional, de que trata a Lei no 9.394, de 20 de dezembro de 1996, o "Programa Escola sem Partido". DF: Magno Malta. Acessado em 26 de março de 2018, de: https://legis.senado.leg.br/sdleggetter/documento?dm=3410752\&disposition=inline

Conselho nacional de justiça - CNJ. (2017). O Poder Judiciário na Aplicação da Lei Maria da Penha. Brasília, DF: CNJ. Acessado em 14 de maio de 2018, de http://www.cnj.jus.br/files/conteudo/arquivo/2017/10/ba9a59b474f22bbdbf7cd4f7e3829 aa6.pdf

Escola Sem Partido. (2018, 28 demarço). Homepage do Movimento. Acessado em 30 de Abril de 2018, de: http://www.escolasempartido.org/

Freire, Paulo. (1970). Pedagogia do oprimido. 7.ed. Rio de Janeiro: Paz e Terra.

Freire, Paulo. (1979). Educação e Mudança. Rio de Janeiro: Paz e Terra.

Instituto Brasileiro de Geografia e Estatística - IBGE. (2018) Estatísticas de Gênero: indicadores sociais das mulheres no Brasil. Homepage da Instituição. Acessado em 30 de Abril de 2018, de: https://biblioteca.ibge.gov.br/visualizacao/livros/liv101551 informativo.pdf

Instituto Brasileiro de Geografia e Estatística - IBGE. Brasil em Síntese. Homepage da Instituição. Acessado em 30 de Abril de 2018, de: https://brasilemsintese.ibge.gov.br/populacao/distribuicao-da-populacao-por-sexo.html

Instituto Brasileiro de Geografia e Estatística - IBGE. Estatísticas de Gênero: uma análise dos resultados do censo demográfico 2010. Homepage da Instituição. Rio de Janeiro, RJ: IBGE. Acessado em 30 de Abril de 2018, de: https://biblioteca.ibge.gov.br/visualizacao/livros/liv88941.pdf

Leão, Andreza M. C. e cols. (2007). 0 machismo dissimulado pela sofisticação: estudo analíticodescritivo da Revista Playboy. Cadernos de formação cultural: experiências e teorias. (4), 7594.

Macedo, Elizabeth. (2017). As demandas conservadoras do movimento escola sem partido e a base nacional curricular comum. Educação \& Sociedade, 38(139), 507-524. Acessado em: 13 
de maio de 2018, de: https://www.scielo.br/scielo.php?script=sci arttext\&pid=S010173302017000200507\&lng=pt\&tlng=pt

Miskolci, Richard, \& Campana, Maximiliano. (2017). "Ideologia de gênero": notas para a genealogia de um pânico moral contemporâneo. Sociedade e Estado, 32(3), 725-748. Acessado em: 15 de maio de 2018, de: https://www.scielo.br/scielo.php?script=sci arttext\&pid=S010269922017000300725\&lng=pt\&tlng=pt

Moura, Fernanda Pereira de. (2016). "Escola sem Partido": relações entre Estado, educação e religião e os impactos no ensino de História. Dissertação (Mestrado). Instituto de História, Programa de Pós-Graduação em Ensino de História. Universidade Federal do Rio de Janeiro. Rio de Janeiro: RJ.

Luna, Naara. (2017). A criminalização da "ideologia de gênero": uma análise do debate sobre diversidade sexual na Câmara dos Deputados em 2015. Cadernos Pagu, (50), s.p. Acesso em 19 de maio de 2018, de: https://www.scielo.br/scielo.php?script=sci arttext\&pid=S010483332017000200311\&lng=pt\&tlng=pt

Rosemberg, Fúlvia. (1994). Educação e Gênero no Brasil. Projeto História. (11) 7-15.

Safatle, Vladimir. (2016). O circuito dos afetos: corpos políticos, desamparo e o fim do indivíduo. $2^{\underline{a}}$ ed. São Paulo, SP: Autêntica Editora.

Silva, Alessandro Soares da. (2007a). Direitos Humanos e Lugares Minoritários: um convite ao pensar sobre processos de exclusão na escola. Em Prograna Ética e Cidadania: construindo valores na escola e na sociendade. Acessado em 18 de setembro de 2011 e Disponível em http://portal.mec.gov.br/seb/arquivos/pdf/Etica/11 soares.pdf

Silva, Salete M. da. (2011). Gênero e cidadania: questões para serem pensadas no quotidiano escolar. Em Costa, Ana A. A.; Rodrigues, Alexnaldo T.; Vanin, Iole M. (2011) Ensino e Gênero: perspectivas transversais. Salvador: UFBA - NEIM, 125-134.

Tonet, Ivo. (2012). Educação contra o Capital. 2ª ed. São Paulo: Luckács. Acesso em 12 de março de 2016, de: http://www.ivotonet.xpg.com.br/arquivos/educacao contra o capital 3a ed.pdf

Recebido em 02/08/2018. 